\title{
'Eco-civic' optimisation: A nested framework for planning and managing landscapes
}

\author{
David Brunckhorst*, Phillip Coop, Ian Reeve \\ Institute for Rural Futures, UNESCO Centre for Bioregional Resource Management, \\ University of New England, Armidale, NSW 2351, Australia
}

Available online 24 June 2005

\begin{abstract}
An important institution for regional resource governance is civic engagement in local affairs, including resource use issues. Local civic engagement has traditionally been structured around local government and, more recently, to catchment-based decision-making bodies. If citizens are to participate in regional resource management in ways that are meaningful to them, it is important that both the landscape units being discussed and the jurisdictional boundaries are meaningful. We have been examining how boundaries for resource management regions might be identified. Three considerations are believed to be important if regional resource management is to be meaningful to the citizens involved. Firstly, that the regional boundaries maximise the areal proportion of the region that residents consider to be part of their 'community', which should lead to greater commitment to civic engagement in resource management. Secondly, that the character of the landscape units within the region possess a high degree of homogeneity, reflecting greater coincidence of interest among the inhabitants of the region. The third consideration is a hierarchical multi-scaling capacity to deal with externalities of resource use. The approach was tested through identification of a series of nested 'eco-civic' resource management regions for north-eastern New South Wales in Australia. The results delineate resource governance regions that nest at local to regional scales for integrated natural resource management. Such 'eco-civic' regions demonstrate a better spatial representation of social and ecological characteristics than existing regional frameworks.
\end{abstract}

Crown Copyright ( 2005 Published by Elsevier B.V. All rights reserved.

Keywords: Institutions; Regions; Resource governance; Social landscapes; Ecological landscapes; Civic engagement

\section{Introduction}

Actions to sustain ecological systems, flows and functions must be integrated across the human dimensions of landscapes (Saunders and Briggs, 2002). The

\footnotetext{
* Corresponding author. Tel.: +61 26773 3001; fax: +6126773 3245 .

E-mail address: dbrunckh@une.edu.au (D. Brunckhorst).
}

foundation for a sustainable future is the continuation of ecological processes across landscapes that are now dominated by human activity. No matter where on the globe, future sustainability will depend on systems of resource governance that mediate the relationship between the society and the economy on one hand, and continuation of ecosystem functional processes on the other. However, conventional approaches to resource governance have often resulted in a seemingly end- 
less recursive loop of problem solving and, occasionally, committed communities to courses of action have turned out to be disastrous (Gunderson et al., 1995; Holling and Meffe, 1996; Power, 1996; Woodward, 2000; Carpenter and Gunderson, 2001; Saunders and Briggs, 2002).

In this paper we use the following meanings for society and its institutions (after Reeve, 1992, 1997, 1998; Shannon, 1992, 1998; Gunderson et al., 1995; Brunckhorst, 2001, 2002). A social system refers to any group of people who interact long enough to create a shared set of understandings, norms, or routines to integrate action and established patterns of dominance and resource allocation. An institution is a repeated, accepted behaviour or action in society. The term 'institutions' refers to sets of formal and informal rules, practices and norms that shape interactions of humans with others, and with nature.

The laws that govern the processes of natural systems are fixed. Therefore, opportunities to improve resource management outcomes significantly will rely on our ability to modify our social systems to serve our long-term interest in the natural world. In practice however, social change seems to be incredibly difficult to achieve. Nevertheless, society and its institutions may need to become more capable of substantial shifts over shorter time scales to adapt to pressures of change, including resource degradation, and adjust towards more ecologically restorative economies (Brunckhorst et al., 1997; Cortner et al., 1998; Carpenter and Gunderson, 2001; Saunders and Briggs, 2002). Such transformations might require novel approaches to find realistic solutions to social and environmental sustainability issues that the citizenry can adopt and adapt with matching civic skills and knowledge (Reeve, 1992, 1998; Brunckhorst, 2002). An increasing number of scientists and policy makers are turning their attention to ecological sustainability issues related to land use, landscape function and ecosystem services, urban infrastructure and services, regional development, policy and institutional arrangements (Forman, 1995; Omernik and Bailey, 1997; Cortner et al., 1998; Knight and Landres, 1998; Turner et al., 2001; Pickett et al., 2004; Reeve et al., in press). This timely shift might be seen as an acknowledgment of a 'regional' concept of 'biocultural appropriateness' that has long been accepted in institutional, urban and agricultural capacity building programs in the developing world (Berkes and Folke, 1998; Johnson et al., 1999; Brunckhorst, 2000).

These approaches also have the potential to create uniquely robust governance institutions that possess the essential dynamic qualities to enable improved adaptive capacities to the emergent processes that constantly challenge rural (non-metropolitan) communities (Reeve, 1992, 1997; Shannon, 1992, 1998; Gunderson et al., 1995; Johnson et al., 1999; Brunckhorst, 2001, 2002). Transformation to a more effective resource governance framework will also draw on the notions of a bioregional framework (sensu Brunckhorst, 2000) and an effective nested arrangement that better represent a community's actual interests in a particular regional landscape while retaining the capacity to address resource governance issues at appropriate ecological scales, creating in effect an institutional interface that bridges social and ecological processes while providing workable administrative arrangements (e.g., for natural resource management agencies, Local Government Areas and other government services; see Berkes and Folke, 1998; Omernik and Bailey, 1997; Reeve, 1998).

Different community and political levels of participation in decision making and broadly inter-connected ecological systems and resource uses need a mutual geography (Stewart et al., 2004; Terkenli, 2005) that brings together shared natural resource issues and their stakeholders at appropriate scales of engagement (Fig. 1). An important institution for regional resource management is civic interest and engagement in local affairs, including resource and land use issues. Local civic engagement has been structured around local government for some 200 years in Australia. State and Federal government resource management agencies have had various administrative regions but, in recent decades, attempts have been made to extend this to decision-making bodies based on river catchments (e.g., Cunningham, 1986). Generally, however, these frameworks for resource governance have not achieved effective engagement, integration or action (Omernik and Bailey, 1997; Knight and Landres, 1998; Reeve, 1998; Parisi et al., 2004). They often seem to produce plans that few are interested in implementing, that have been 'captured' by single interests (not representative; small proportion engaged or participating) or that split inter-related issues into multiple single-issue frameworks (e.g., vegetation 


\section{Loss of capacity of ecological resource base (land degradation, reduced quality of ecosystem services, lost agricultural production)}

Gives rise to need for integrated resource management

\section{Citizens and Communities} have an interest (individually and collectively citizens are interested in resource use)

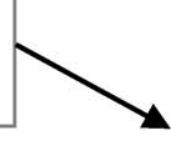

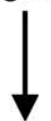

Gives rise to need for consultative and participatory approaches, engagement and collective action

Past experience and policy history suggests single resource issue areas for NRM don't work very well

There is a limit to the size of a consultative unit

The consultation and engagement task can be organised spatially, but difficult to achieve effective representation

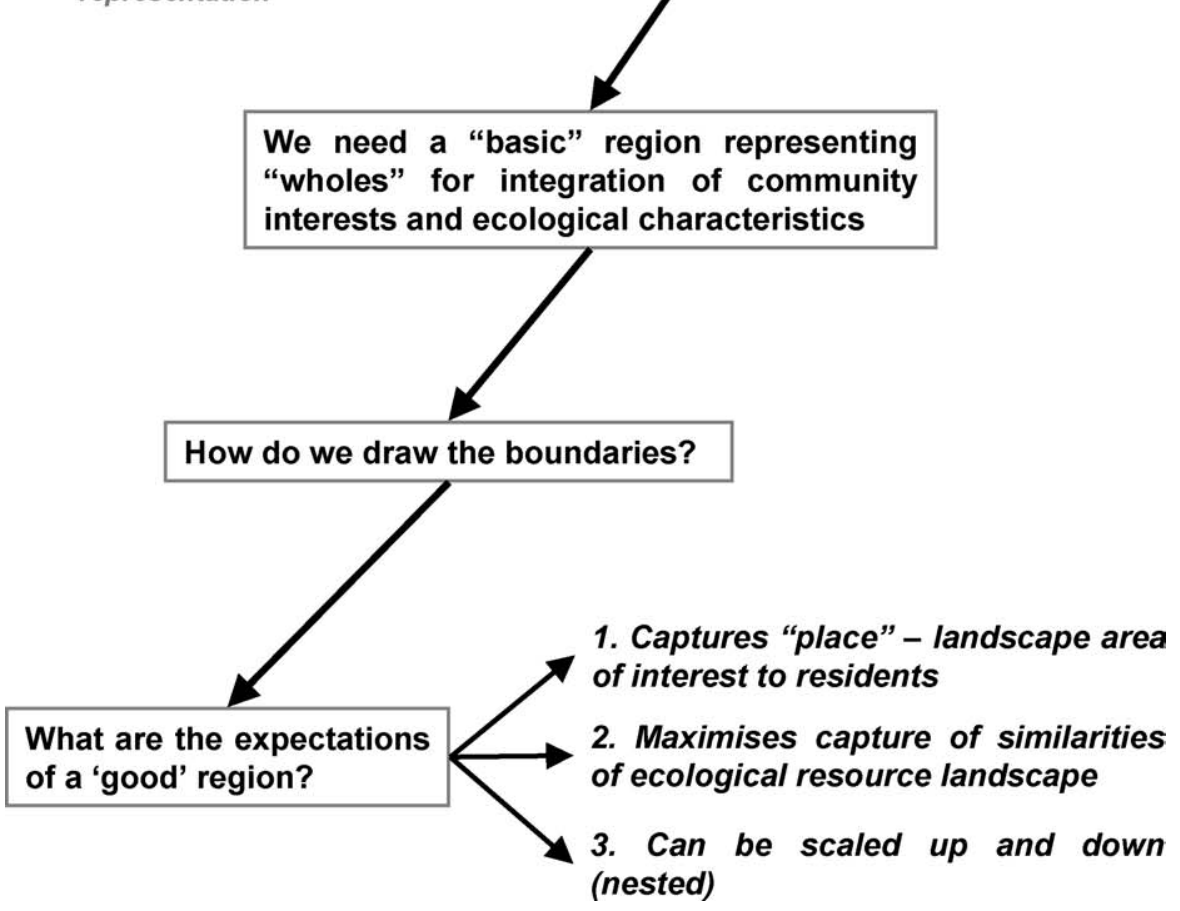

Fig. 1. Designing a region for natural resource governance and management. Diagram showing conceptual model for methodological design. In recognising the need for a basic 'holistic' region to integrate community interests with ecological characteristics, this project focused on developing a method to identify boundaries that met the three primary expectations of such regional frameworks for more effective resource governance. 
regions, catchment regions, forestry regions) (Power, 1996; Brunckhorst, 2000; Parisi et al., 2004). Novel approaches to defining multi-functional, but characteristic, social-ecological landscapes could provide more efficient and socially appropriate regional frameworks for community and agency engagement in resource governance.

The work reported here, building on earlier work (Brunckhorst and Rollings, 1999; Brunckhorst and Coop, 2001), contributes one approach towards catalysing more participative institutions for resource governance, planning and management. The current work focused on development and trial of a methodology to map the extent of the strength of community interest in a geographic area (Coop, 2003) and, combining these with biophysical areal units of similarity delineate 'functional' zones ('eco-civic' regions) for resource governance.

\section{Approach}

These current concerns and issues related to policy, planning and delivery frameworks for effective and efficient natural resource management and governance raise the questions (Fig. 1):

- If resource management is to occur at a regional level, on what grounds can we make choices in defining the administrative regions within which this management occurs?

- If we have an understanding of what might make one region preferable to another, how can we operationalise this into a procedure that reflects this understanding?

- How will this procedure draw boundaries for the chosen regions?

The creation of a resource governance institution that draws on these social resources and matches them to the local community territory can form the foundation of an effective nested (multi-scale) resource governance framework. Integration of ecological functions and influences of landscapes for natural resource management and governance suggests a regional framework should maximise the homogeneity of the landscape units within the region (Bailey, 1996).

There are two significant elements arising here. Firstly, the association by the local (human) communi- ties to their natural landscape characterised by particular ecosystems and vegetation. This includes attachment to the visual elements of the landscape and to the resource utilisation by these communities including land use issues, further embedding communities into their landscape through the creation of a cultural (agricultural, urban) landscape (Shannon, 1992, 1998; Field et al., 2003; Parisi et al., 2004; Stewart et al., 2004; Terkenli, 2005). Secondly, there are other benefits arising from the management of a relatively homogenous landscape. Efficiencies arise in the construction and maintenance of infrastructure, requirements for specific equipment and, in various land uses with knowledge of the behaviour of the local soils and vegetation under different conditions such as flood, fire and drought (Power, 1996). In other words, the ecological landscape context for resource management is made up of fairly similar biophysical characteristics. For example, the soils, geology, elevation climate and topography combine to provide a relatively homogeneous ecological resource base (Belbin, 1993; Forman, 1995; Omernik, 1995; Bailey, 1996).

Both ecological systems and social systems are inter-connected at broader scales. While biophysical structures provide ecological function and services important to communities and land uses at one level, they interrelate to other landscape systems, land uses and communities at broader scales (e.g., whole catchments or adjacent catchments and political systems such as Local Government Areas; see Saunders and Briggs, 2002).

Therefore regional frameworks for natural resource management and governance must be able to scale up from local to broader regional contexts as appropriate for effective resource management and administration, while maximising capture of communities' areas of interest and similar natural landscapes. A loosely networked hierarchy (Slocombe, 1983; Meidinger, 1998) that captures communities of common interest and similar natural landscapes might also balance bottom-up citizen participation and engagement with administrative control while allowing for variable task organisation, knowledge sharing, efficient resource use, coordination and integration (Meidinger, 1997, 1998; Reeve, 1998; Shannon, 1998, 2000; Rollings and Brunckhorst, 1999; Brunckhorst, 2000, 2001; Marshall, 2001). Fig. 1 summarises the conceptual argument for developing 
a method to identify boundaries that meet the three primary expectations of regional frameworks for more effective resource governance, planning and management.

The regional framework is required to do three things. Firstly, to maximise the spatial capture of 'sense of place'; that is, the landscape area of interest to residents and in which they are willing to engage in decisions for the future. This requires that the governance region encapsulate the largest proportion possible of the areas that residents regard as their 'community'. Secondly, to maximise the spatial capture of similarities of the ecological resource base (homogeneity of the biophysical landscape; Fig. 2). The third condition is that regions within the framework are capable of being scaled up from a local level to broader regional con- texts (nesting) while not compromising the first two principles (Figs. 3 and 4).

\section{Methods}

The following summarises the methods developed and applied in this project. Full details of the methodological development, testing and statistics (Coop, 2003) are not all reported here, but are available from the authors on request. In essence, the methodology is to provide for the three important conditions expected of the regional frameworks discussed above (Figs. 1-4).

A mail survey with a range of questions and maps was designed to elucidate, in a data form compatible

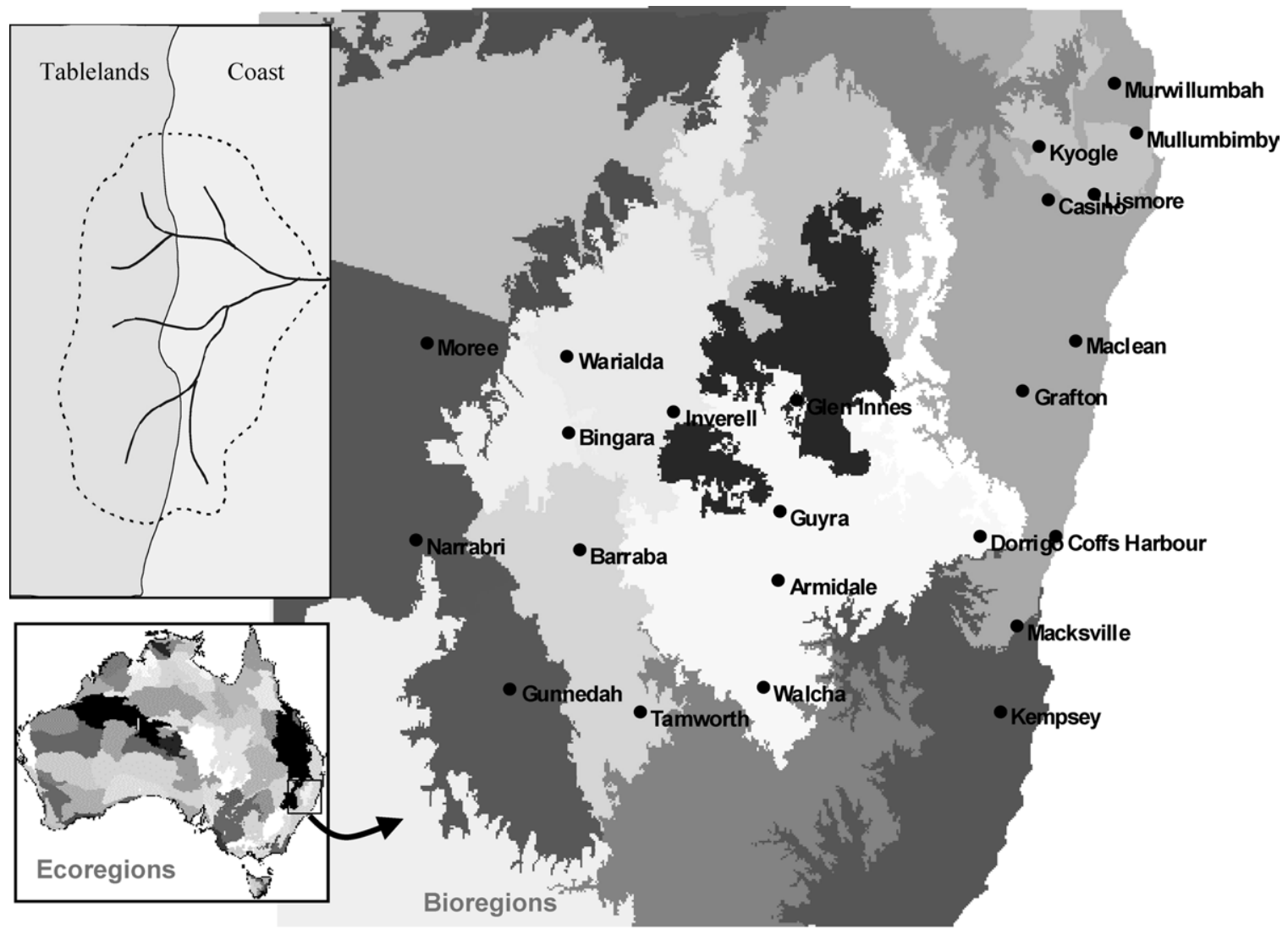

Case study area for methodology

Fig. 2. The resource governance region must have a reasonable degree of spatial correspondence with the 'natural' landscape. Examples shown here include a tablelands and coastal plains landscape intersected by a catchment and, Australian ecoregions from the Interim Biogeographic Regionalisation of Australia (Thackway and Cresswell, 1995), with our finer scale biophysical landscapes of the study area. 


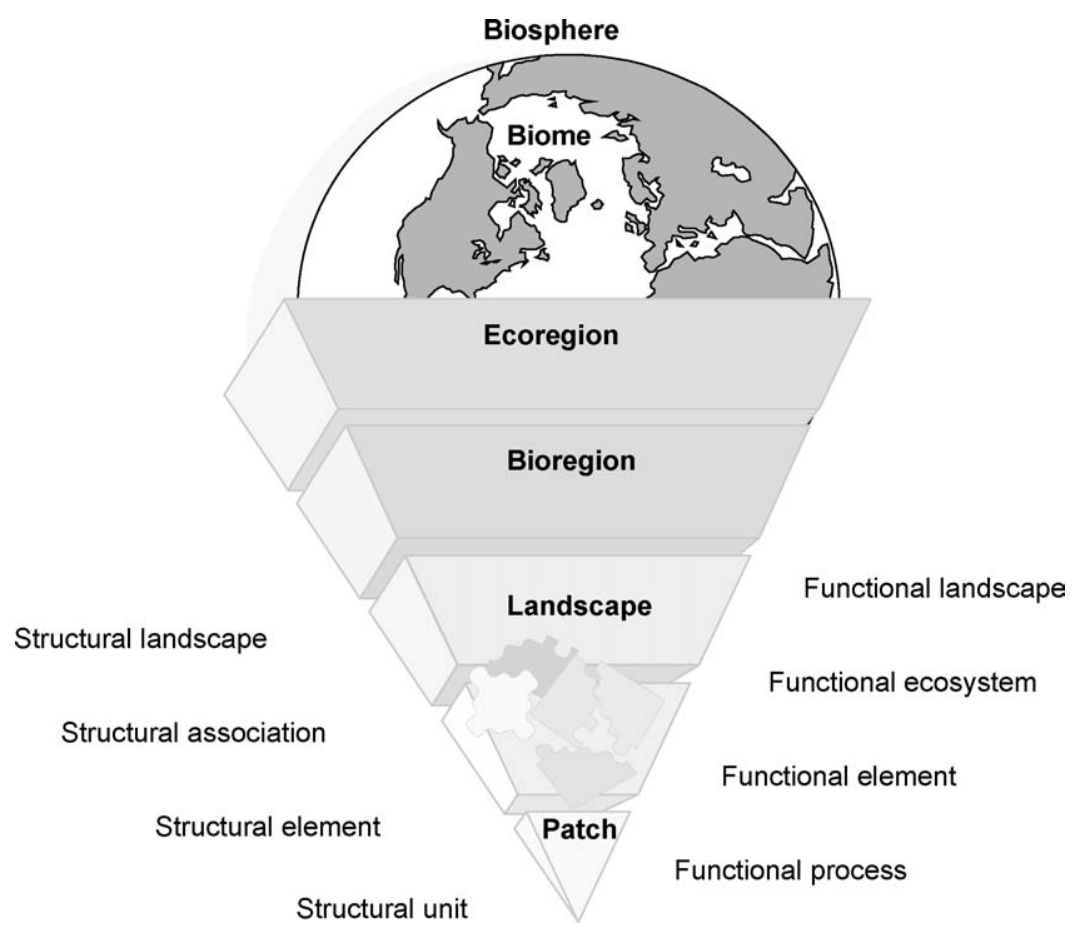

Fig. 3. Nesting of structural and functional components of ecological units (after Brunckhorst and Rollings, 1999; Brunckhorst, 2000, 2001). Human interaction with the environment occurs mainly at landscape scales, but across relatively short time periods.

with GIS mapping, the areas of interest to residents and what area they considered as their 'community'. The survey and several maps and map scales were tested on a small number of country town and rural residents and then further refined (a copy of the survey is available from the authors on request).

The method developed needed to be compatible and integrated for: random survey sample with spatial evenness; appropriate mapping scale (1:1 million when scaled up from postcode areas); overlap mapping to avoid artificial boundaries; data sources Australian Bureau of Statistics Census, Postcode, Federal Electoral Areas; spatial unit of Postcode Area; and, spatial database design (requiring very large capacity for several hundred thousand records as well as capability to link to GIS data tables).

A sample of 10,500 was required to provide a spatially even spread of data across the entire study area of northern New South Wales. This is around a five-fold larger sample than a standard social survey (e.g., market survey) would require for the given population across this region. The large sample and expected return rate was required to ensure statistical validity of spatially even sampling across the entire region for mapping and analysis purposes. A response rate of $23 \%$ provided acceptable confidence limits for spatial evenness at postcode area scales. However, the data were also scaled up for mapping, which provided improved (statistical) levels of confidence.

The key question framing in the survey that provided the data for the analysis presented in this paper followed a series of questions in which respondents were asked to indicate the names of towns they visited in their region, the frequency of these visits, the location of these towns on a map provided with the questionnaire and the location of where they lived. They were then asked:

Often, people feel they belong to a community associated with a particular area or district. On the same map, please draw a line around the area to which you have the greatest sense of community attachment.

The line drawn by each respondent was digitised in a GIS as a polygon. Consequently, any particular 


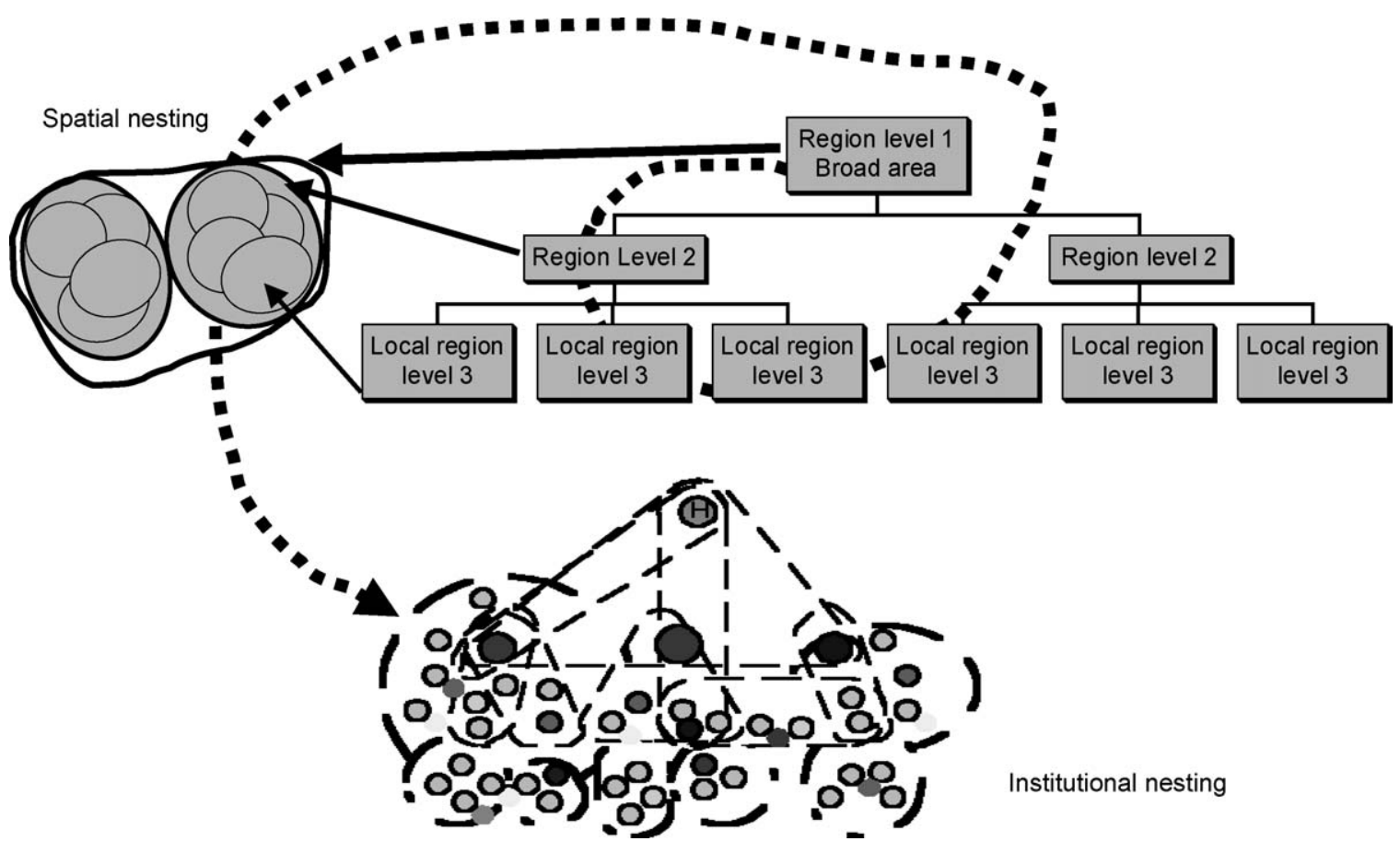

Fig. 4. The principle of nesting also facilitates a loosely networked hierarchy that captures communities of common interest and similar natural landscapes, balancing representative participatory processes with administrative control (after Meidinger, 1997, 1998; Shannon, 1998).

geographical point in the study area could have one or more (or none) of these polygons overlapping it.

\section{Results}

The GIS was used to produce a map that showed, for each point in the study, the number of polygons overlapping it. Each resident's identified community area has a single value as a polygon. Overlapping polygons therefore provide height and shape to the map producing a community topography or social landscape (Fig. 5). The community topography is represented as a threedimensional social surface in the GIS. It provides a geocoded surface within which the depth and spatial configuration of valleys can be analysed for potential boundary placement. We have termed the surface a 'social landscape' as it is a measure of the spatial distribution of the degree of attachment by people to their biophysical surroundings. The social landscape can be examined in the GIS as a surface, with the peaks on the surface indicating a larger number of overlapping polygons, and valleys representing parts where there were few or no polygons (Fig. 6). The peaks represented localities with greater numbers of people who regarded that locality as part of their community. The valleys represented localities that were regarded as part of their community by relatively few people, or no one. These valleys therefore represent the 'breakpoints' that identify the spatial extent associated with a particular community.

A GIS hydrological analytical tool (ESRI Arcview 3.2) delineated a 'drainage network' on the social 'topography' surface. The 'valleys' define linear zones in which an administrative boundary would intersect the minimum number of the polygons representing the area which people regard as their community (Fig. 7). In other words, boundaries of these regions minimise the number of residents in the undesirable situation of the boundary cutting through their area of interest, and to maximise the number of people 'encapsulated' within a regional boundary that best matches their area of collective interest. This provides a socially optimal solution that captures sense of place and civic 


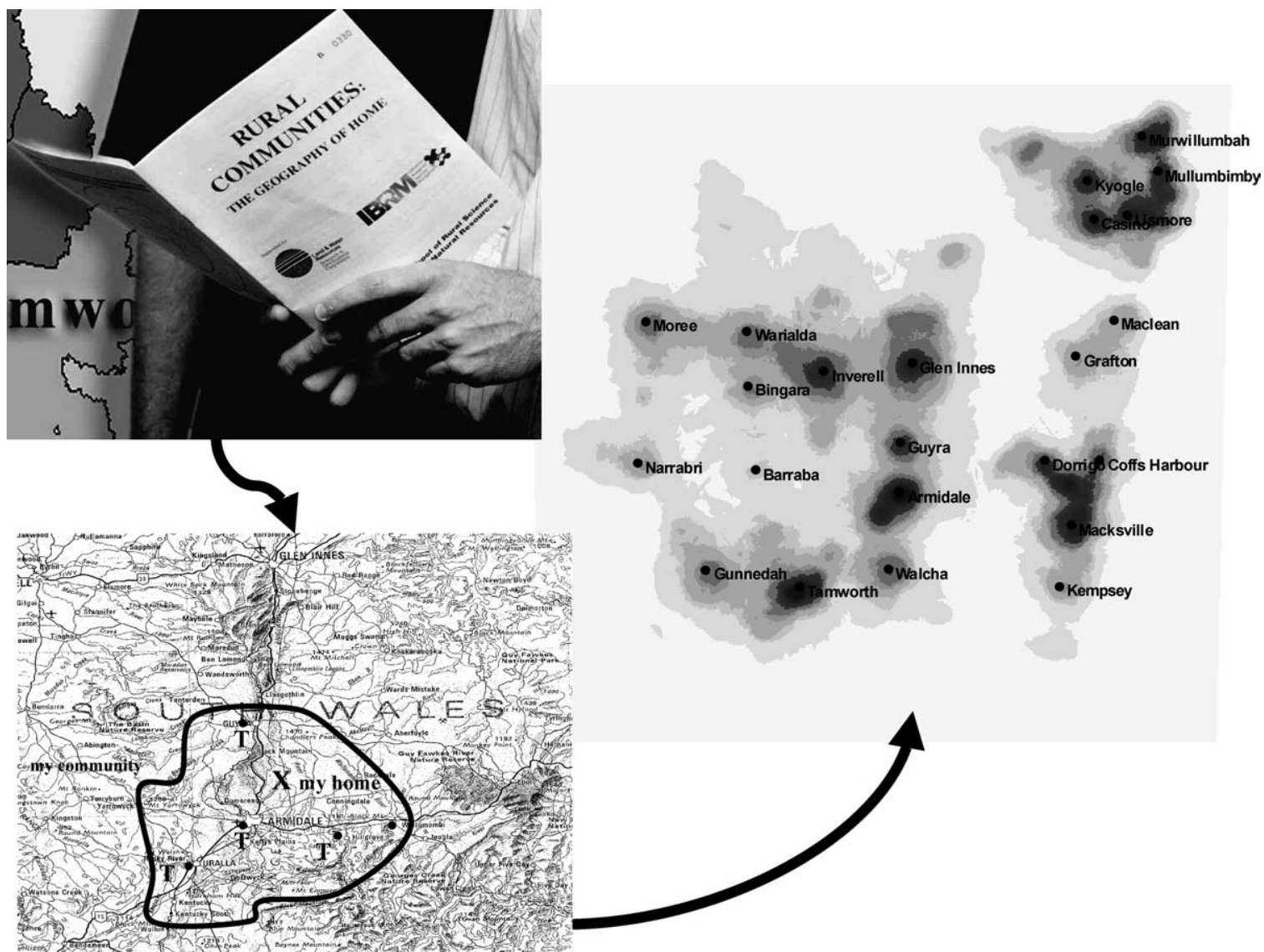

Fig. 5. Sequence of social survey and mapping to develop the social landscape. Social survey responses on various question framings were digitised or captured into the GIS to produce a geo-referenced community landscape surface.

motivation for a definable region. It also identifies the 'order' of the nested hierarchy for institutional arrangements.

Having defined the 'drainage network' of the social topography, it is possible to identify 'valleys' that divide northern New South Wales into regions, each region having 'upland areas' (i.e. areas where the social surface is relatively high). Some regions have their own 'valleys' intersecting them, which can be used to further divide these regions into sub-regions. Some subregions can be further divided along 'valleys' within them. The 'valley' used in each successive division of a region or sub-region is at a slightly higher level than the 'valley' used in the previous division. The division process can therefore start by finding the lowest 'valley' that intersects the whole area of interest, and then repeating this for each of the two regions separated by this 'valley', and so on (Fig. 7).

The result is a nested hierarchy of regions and subregions, with boundaries that are optimal in the sense that they minimise the number of people who have the area they regard as their community intersected by a region or sub-regional boundary, and maximise the number of people who have the area they regard as their community wholly contained within a region or sub-region. We have termed these regions and subregions 'communities of shared interest' to reflect the fact that people within a particular region or sub-region tend to have similar areas of the biophysical landscape that they regard as their community.

The broadest level of the nested hierarchy (Level 1) divides the northern New South Wales coastal commu- 


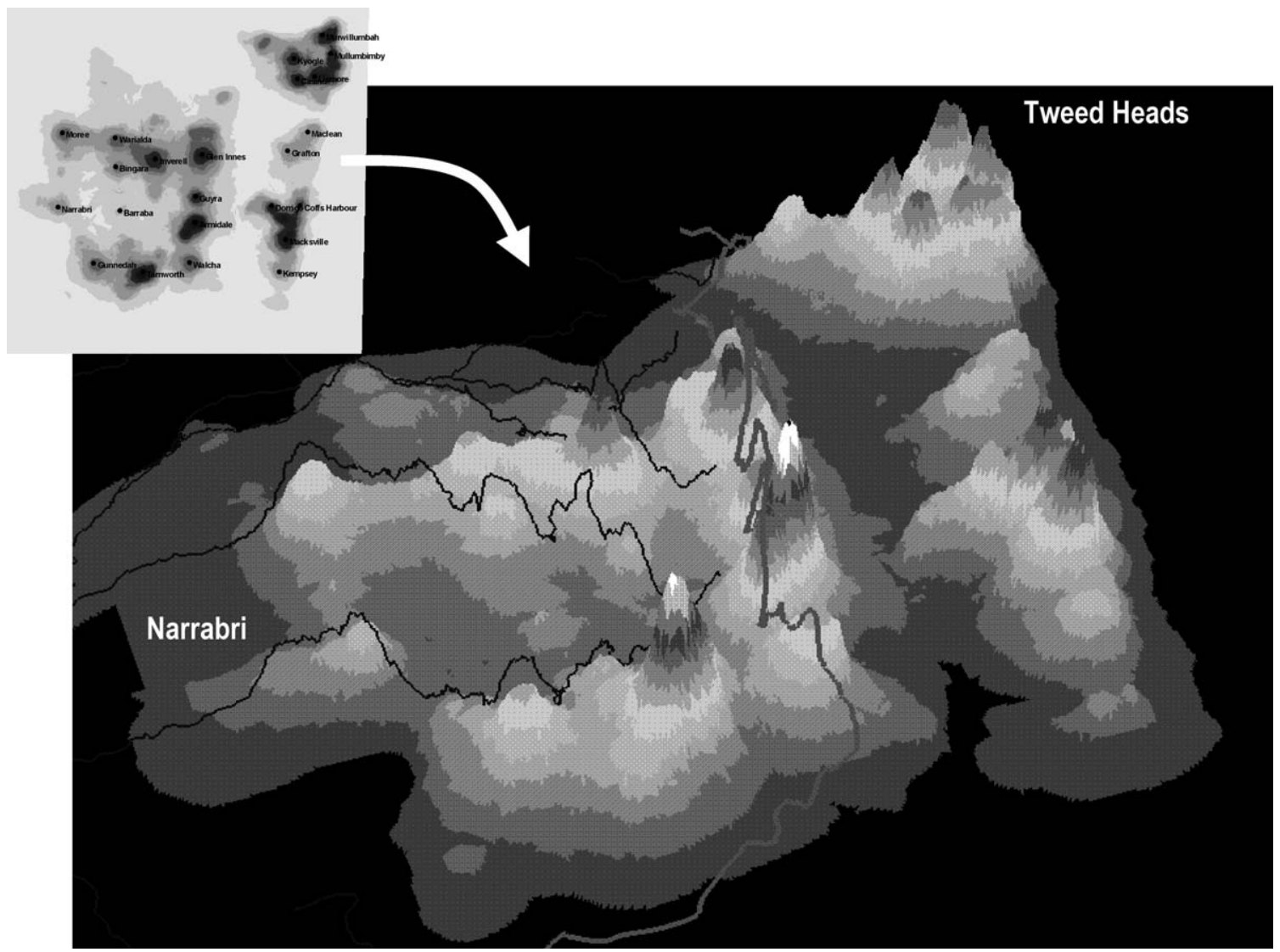

Fig. 6. The social landscape or community surface, topography for north-eastern New South Wales in three-dimensional view. The peaks represent areas regarded by relatively large numbers of people as part of 'their community'. The valleys represent areas regarded in this way by relatively few people.

nities, along the top of the escarpment, from the New England Tablelands and North West slopes (Fig. 8). The Level 2 and Level 3 sub-regions, or communities of shared interest can be clearly defined also (Fig. 8). A finer scale division might be possible. The confidence limits of the survey data and mapped community polygons do not allow further division.

Ecological landscapes were described hierarchically using GIS classification or regionalisation of multi-attribute data including geology and derived soils, soil moisture, climate surfaces, elevation and topography (Fig. 9). For effective natural resource management and governance according to our principles, there is a need to optimise citizen engagement in resource governance processes within relatively homogeneous ecological resource landscapes.
The nested resource governance regions were identified via 'eco-civic' optimisation. Optimisation provides for the best geographical fit of communities of shared interest (social catchments) with ecological landscapes at three inter-related (nested) scales, while minimising the number of people having the area they regarded as their community intersected by the boundaries between the regions. The decision rule stops movement of a boundary as soon as the social landscape surface begins to rise steeply out of a 'valley' in the surface.

Consultation and feedback from community stakeholders and government agencies occurred throughout the project. This provided additional 'ground-truthing'. Feedback helped to simplify some of our overly technical theory and jargon down to the three conditions for a 


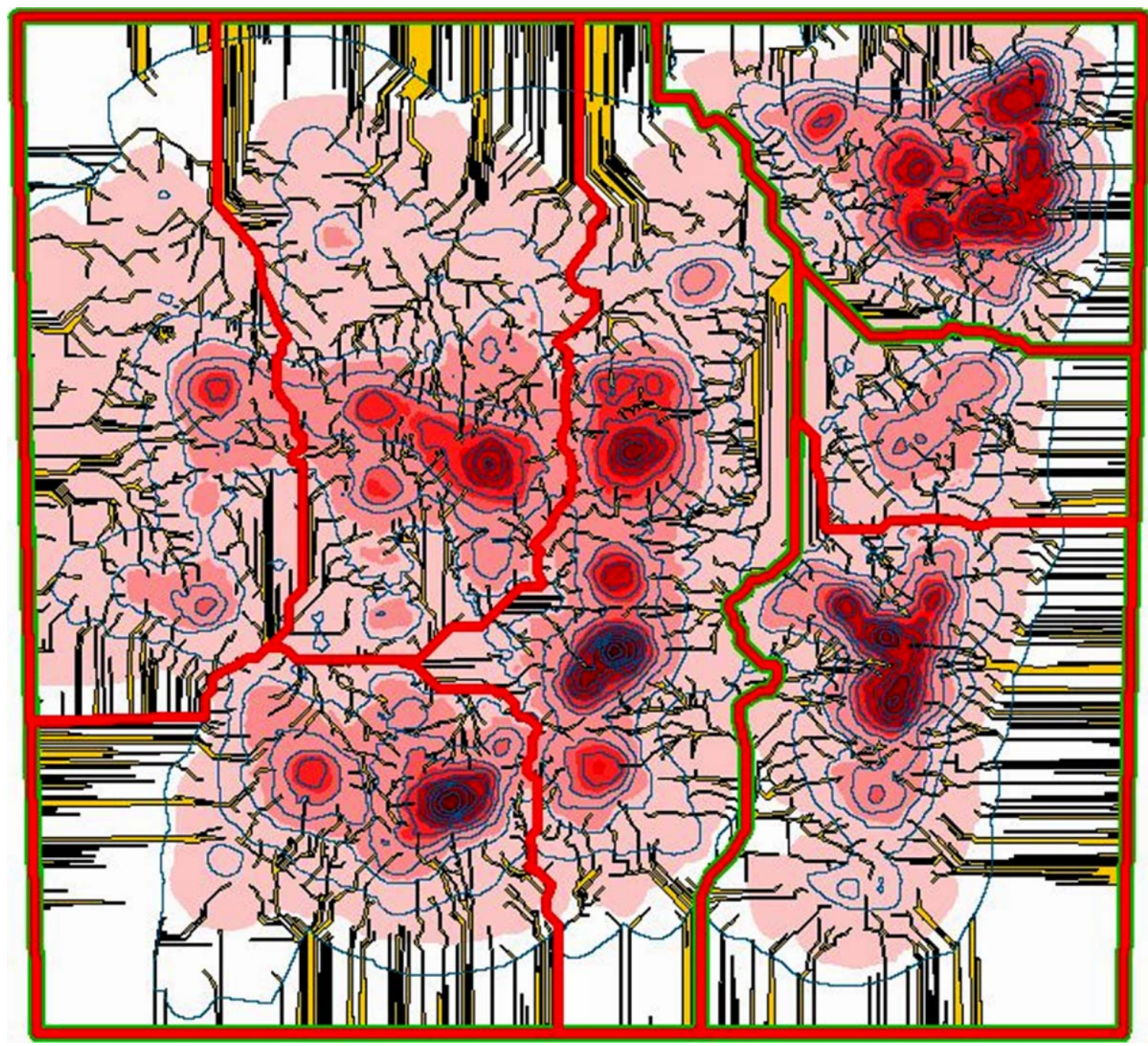

Fig. 7. Application of a hydrological model to the social landscape. The 'valleys' define linear zones in which an administrative boundary would minimise the number of people who have the area they regard as their community intersected by that boundary.

regional framework described earlier. These conditions guided our methodological development and its application to the case-study area for further development.

\section{Discussion}

\subsection{Location, location, location}

To enable the comparison of the nested resource governance regionalisation and other public adminis- trative regionalisations currently in use, the concept of the Community Capture Index was developed. This is the proportion of survey respondents for whom the area regarded as their community is contained within the boundary of the region or administrative area.

Local governments are important natural resource managers in Australia as well as playing a role in environmental planning, water and waste management and development controls. Our case-study area contained 36 Local Government Areas. The study shows very clearly that the areas that people today think of as their 


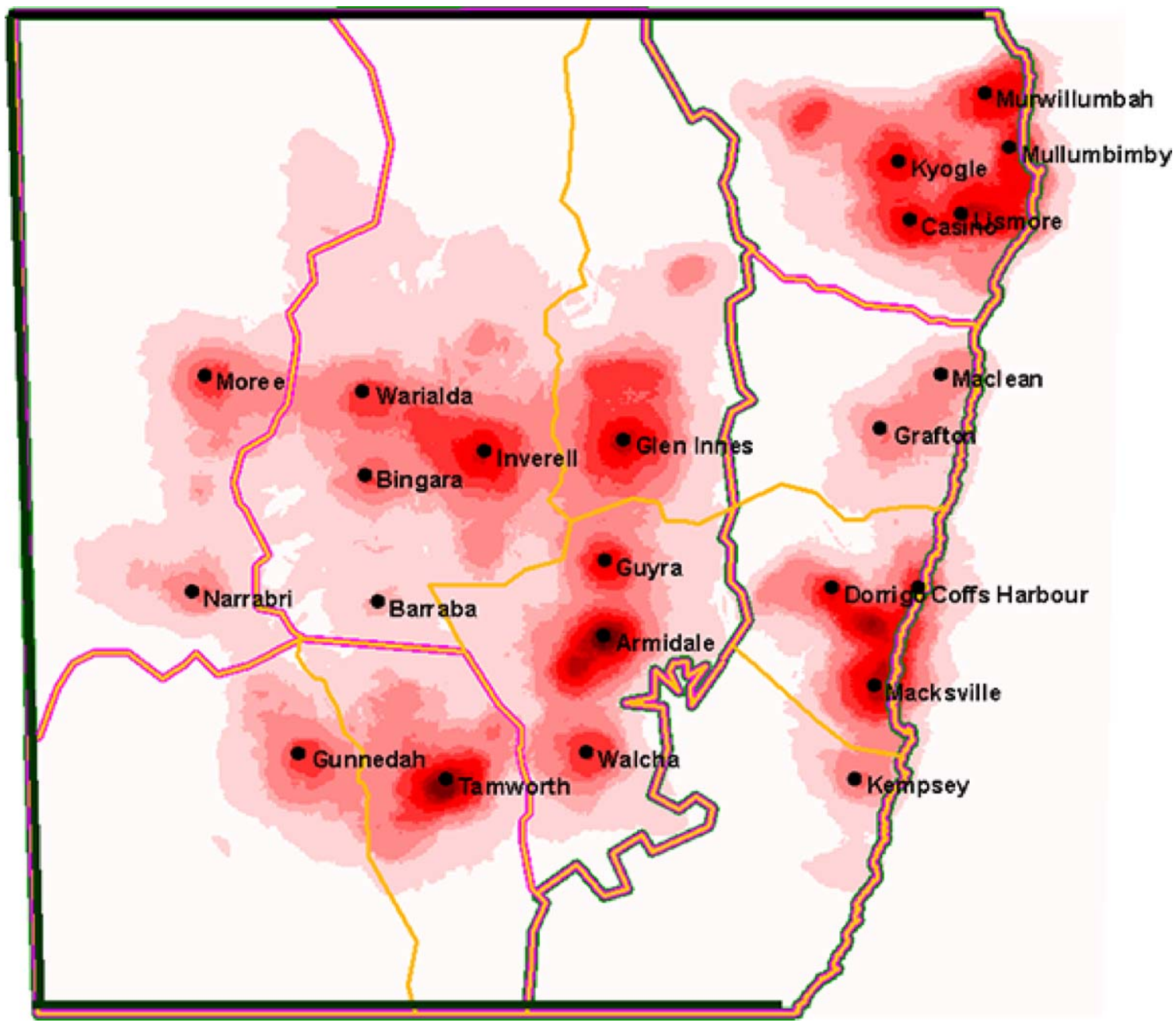

Fig. 8. The three nested levels of regions and sub-regions that maximise the capture of areas people regard as their community, and minimise the intersection of these areas by regional and sub-regional boundaries.

community are often cut through by local government boundaries. For all respondents, these areas were larger than those within the current local government boundaries.

A Community Capture Index value was calculated for each Local Government Area in the study area. An interesting bimodal distribution resulted when Community Capture Index was graphed against the percentage of respondents in each Community Capture Index category for each of the 36 Local Government Areas (Fig. 10). Most respondents had only about $10 \%$ of the area they regarded as their community within their Local Government Area.
When public administrative boundaries cut through relatively high areas on the social landscape, as shown in Fig. 11, they end up 'capturing' more 'valleys', i.e. where there are relatively few people who regard that area as part of their community. Overall, the mean Community Capture Index for all the Local Government Areas in the study area was less than $10 \%$. In fact, Local Government Areas perform worse than a completely random allocation of boundaries, as governance regions would perform in terms of their potential to capture the area of civic interest to residents (Fig. 12). This simply means Local Government Areas are in the wrong place; they tend to straddle 'valleys' 


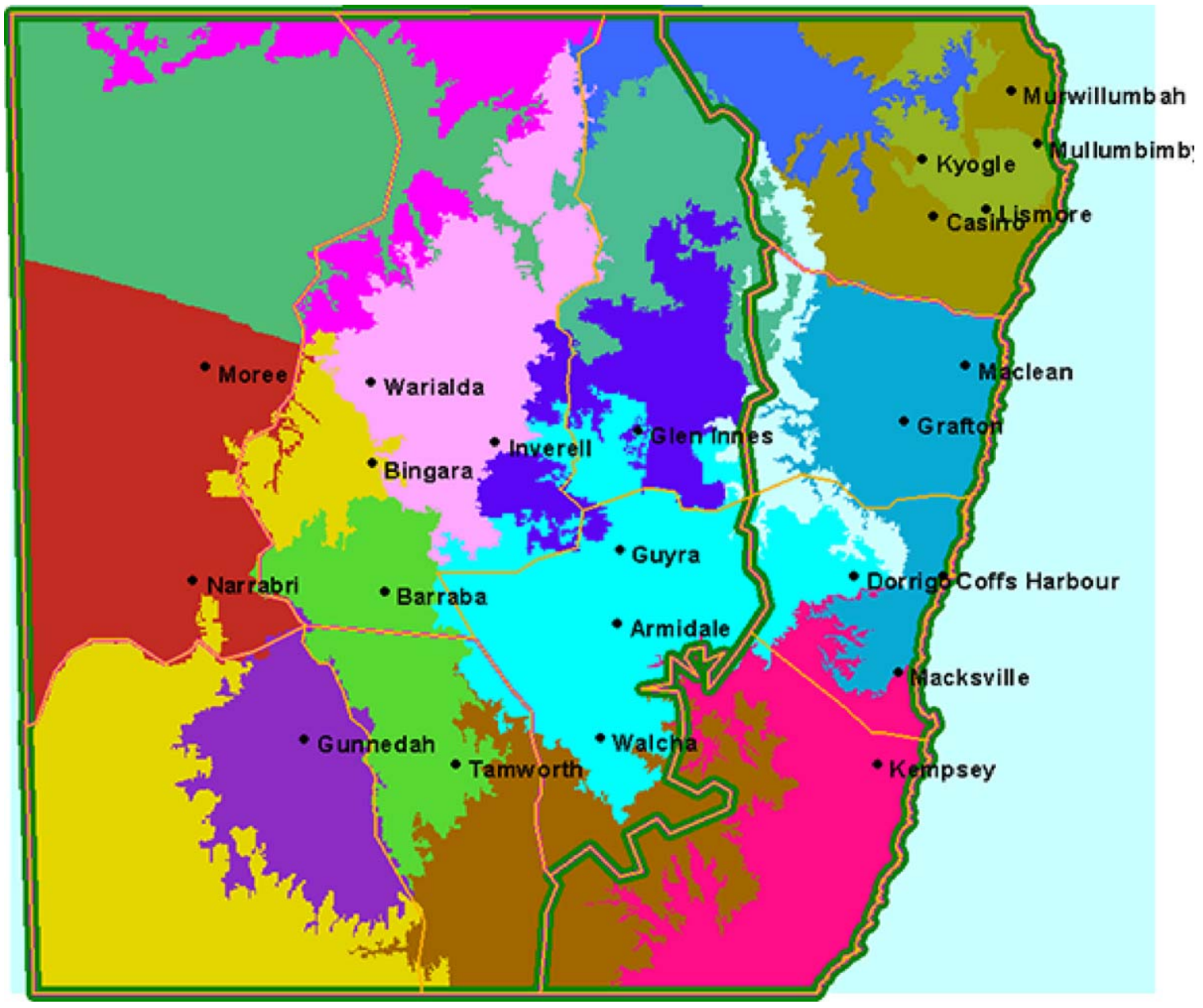

Fig. 9. Ecological landscapes with three levels of communities of shared interest. 'Eco-civic' optimisation identifies nested resource governance regions by allowing 'juggling' of boundaries to maximise inclusion of homogeneous landscapes and the inclusion within the regions of the areas that people regard as their community.

in the social landscape, rather than encircling elevated regions of the community topography. Amalgamating Local Government Areas into larger areas will therefore not improve performance beyond random. It is not surprising that State government agency regions perform so poorly as well, because such administrative regions are usually larger groupings of Local Government Areas.

Community Capture Indices for a number of biophysical regions (e.g., Interim Biogeographic Regionalisation of Australia (Thackway and Cresswell, 1995) or catchment management areas) were also calculated (Figs. 11 and 12). These also performed relatively poorly. Catchment boundaries and local government boundaries divide the very communities that have an interest in the future of their local region and, indeed must work together towards a sustainable future. To improve performance, boundaries must change. They need to be in the right location.

Community Capture Indices were calculated for public administrative regions, such as those used by New South Wales Agriculture, Planning Department, Environment Protection Agency, Agriculture Department and Premiers Department. These regions are larger than Local Government Areas and might, for this reason, be expected to capture a larger proportion 


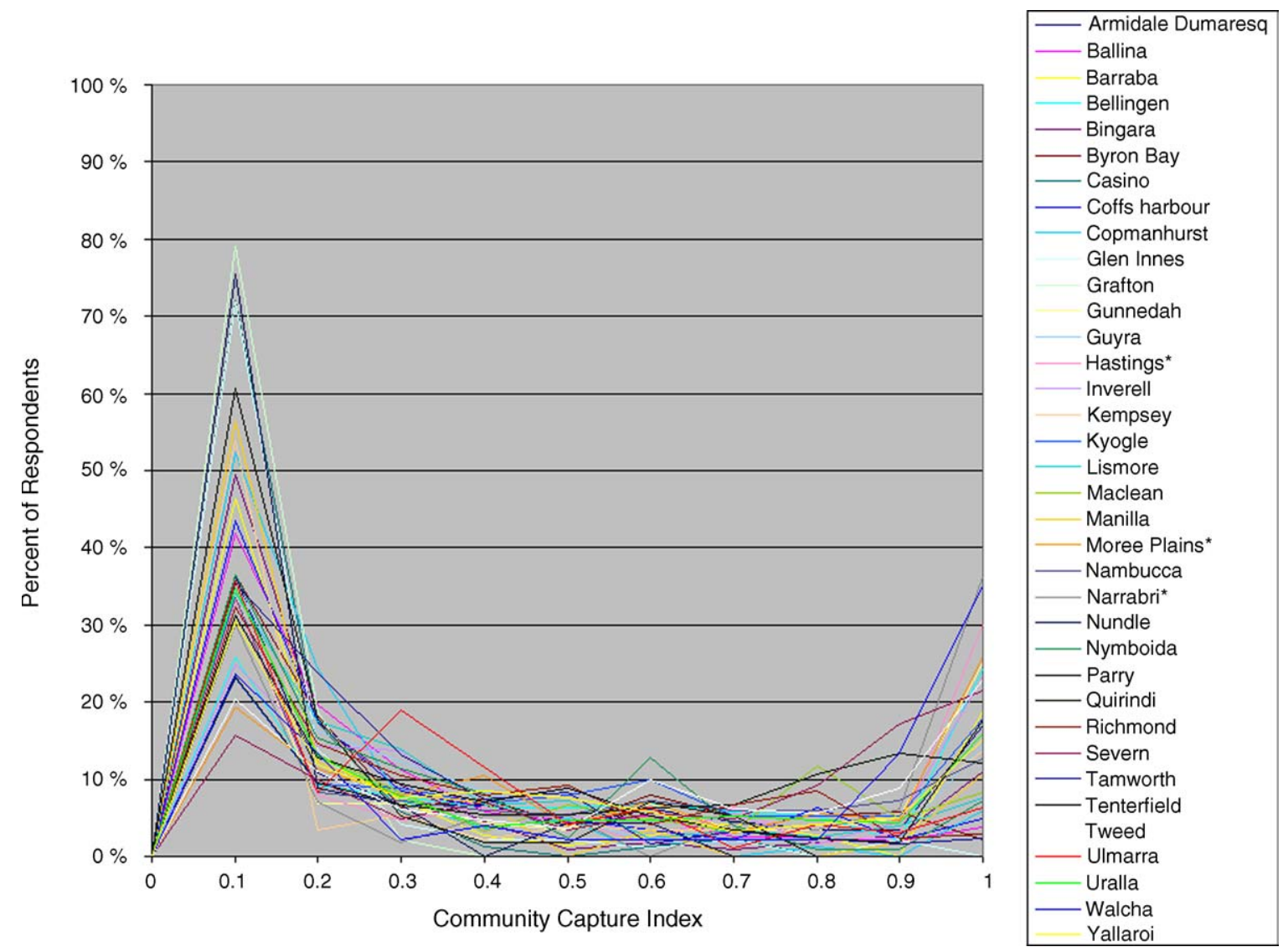

Fig. 10. The bimodal distribution of percentage of respondents' area of interest 'captured' by Local Government Areas. Most respondents' area of interest fell outside their Local Government Area.

of the areas regarded by survey respondents as their community. This was found to be the case, although these administrative regions still did not perform any better than if regions of similar sizes were randomly generated (Fig. 12).

All three levels of the nested resource governance regions derived by eco-civic optimisation (Fig. 9) perform much better than existing administrative regions of similar size (Fig. 12). These regions would provide a more suitable administrative regionalisation for any area of public policy and administration that requires some form of community participation in collective decision-making. Such areas include resource governance, ecologically sustainable regional development, natural resources management, and the delivery of some state and local government services.

\subsection{Eco-civic regions for resource governance}

There are an increasing number of case studies (e.g., Berkes and Folke, 1998; Brunckhorst, 2000, 2002) and resource governance examples (Gunderson et al., 1995; McKean, 1996; Johnson et al., 1999) demonstrating the value of matching scales of social-ecological systems. Redesigning spatial frameworks for resource governance arrangements is no easy task, but might be critically important to civic dialogue, action and adaptation towards future sustainability.

The results of this project are immediately relevant. On one hand they show why purely biophysical or purely political administrative regions may be an impediment to participation, engagement and action by communities. The results also show that political jurisdictions like local government are not representa- 


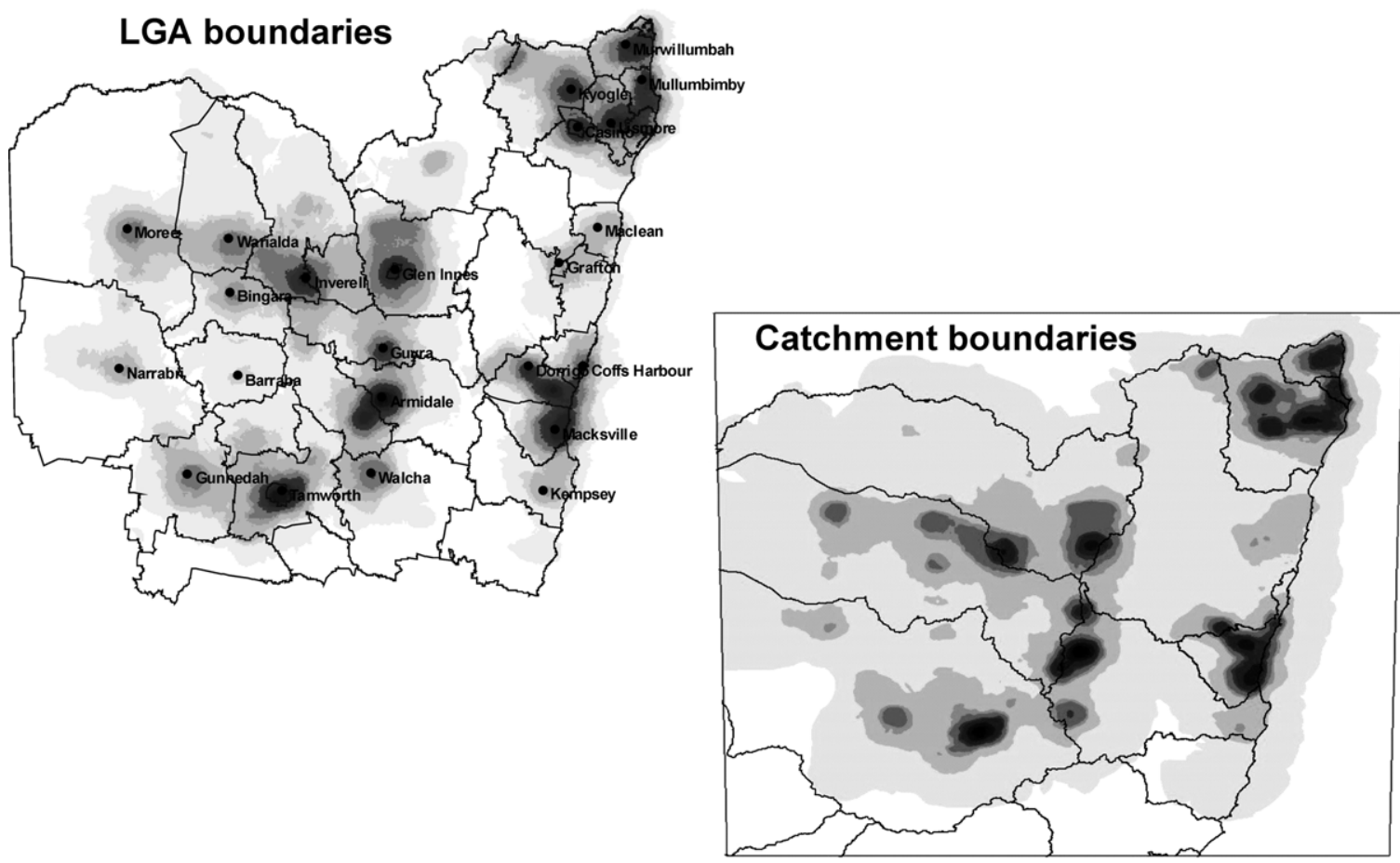

Fig. 11. Existing Local Government Areas and Catchment management boundaries overlaid on the social landscape. Catchment and Local Government Area boundaries are located in the wrong place, splitting the very communities that need to work together for a sustainable future.

tive of their residents and communities. If there is a need for people to work together with a local council to build a sustainable future in rural Australia, it will be a lot easier and produce a better result, if that council covers the area people think of as their community. The New South Wales government has been considering council amalgamations for some time and encouraging voluntary amalgamations of Local Government Areas without boundary changes. Our results show that unless boundaries are changed, areal representation and the potential for engagement in local regional issues will not improve. The methodology developed here is applicable to any non-metropolitan area. It could be valuable in determining better regional arrangements for the Natural Heritage Trust, National Action Plan, Murray Darling Basin Commission and other national or state natural resource management policies and programs. There are lessons for catchment management too. Perhaps integrated catchment man- agement might be re-interpreted to include the understanding of community identity with different parts of catchments, possibly across the top of several catchments. Policies, programs and community action could be planned to 'nest' up towards the ultimate, whole catchment targets.

The adoption and application of this new method to re-defining regional natural resource management frameworks along with local government and other service delivery might be seen as a very big step to take. However, it is not impossible, because the 'eco-civic' regions maximise capture of the area of interest to most residents and communities and, therefore is likely to be politically palatable in terms of reform implementation. Feedback via media, radio talk back and other stakeholder networks has also indicated a tremendous willingness by the local communities and businesses to pursue such change. Local politicians and resource stakeholder groups say this is not surprising, because, 


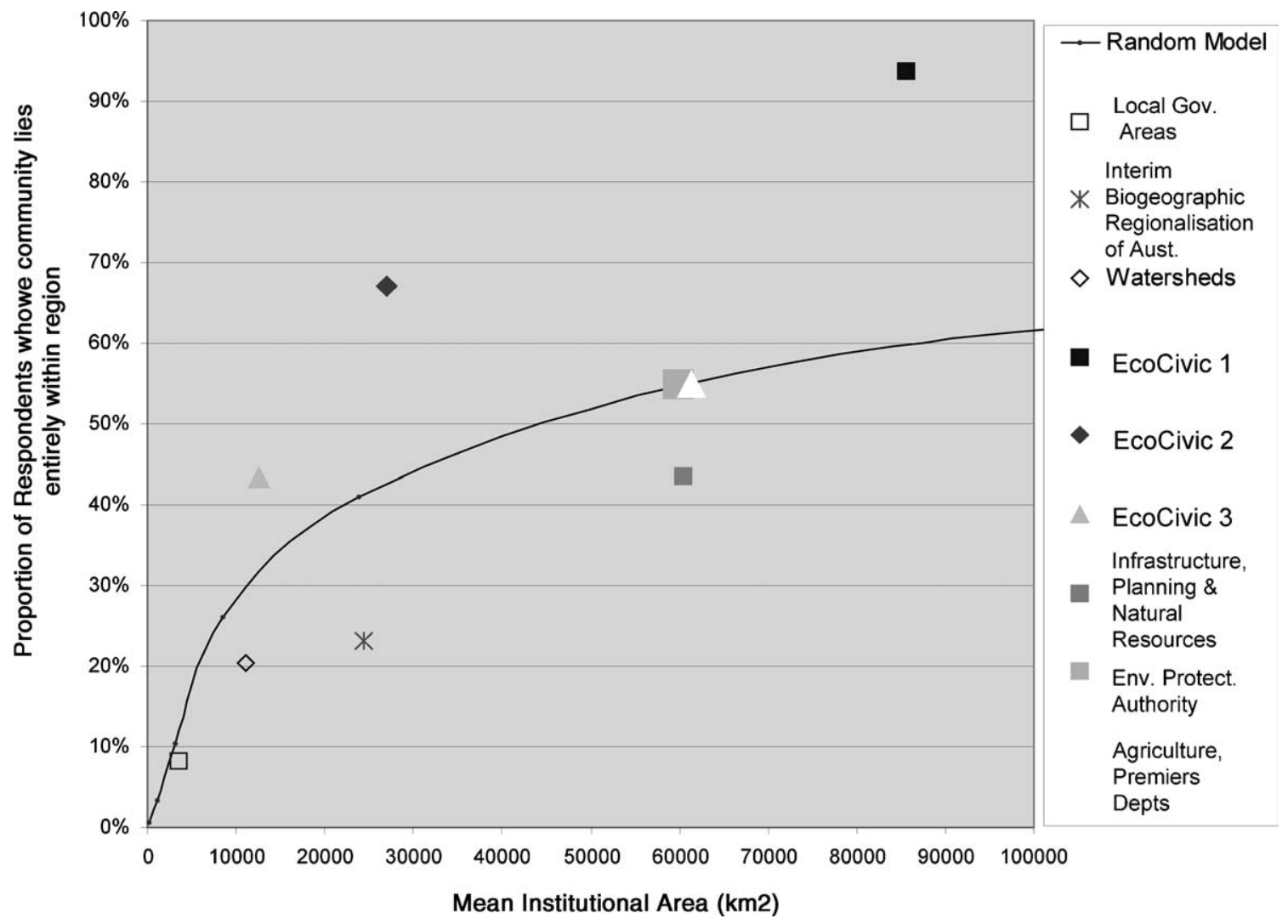

Fig. 12. Community capture plotted against mean institutional governance area. All three levels of 'eco-civic' regions perform much better than existing administrative regions of similar size.

it is obvious that it reflects the identity and interests developed and represented by communities and their interactions. It has become apparent that our results are particularly relevant, not only to natural resource planning, management and governance issues of integration and coordination, but also to other related areas for 'whole of government' service delivery and Local Government Areas. Such regional frameworks may serve in the future as a common framework for Federal and State natural resource management programs, as well as State Government and local government.

\section{Acknowledgements}

Our thanks to Land and Water Australia for funding this research. The feedback and comments of many colleagues on various stages of the work and, colleagues and referees for suggestions to improve this manuscript was greatly appreciated.

\section{References}

Bailey, R.G., 1996. Multi-scale ecosystem analysis. Environ. Monit. Assess. 39, 21-24.

Belbin, L., 1993. Environmental representativeness: regional partitioning and reserve selection. Biol. Conserv. 66, 223-230.

Berkes, F., Folke, C. (Eds.), 1998. Linking Social and Ecological Systems: Management Practices and Social Mechanisms for Building Resilience. Cambridge University Press, New York.

Brunckhorst, D.J., 2000. Bioregional Planning: Resource Management Beyond the New Millennium. Harwood Academic, Amsterdam.

Brunckhorst, D.J., 2001. Building capital through bioregional planning and biosphere reserves. J. Ethics Sci. Environ. Pollut., 19-32.

Brunckhorst, D.J., 2002. Institutions to sustain ecological and social systems. J. Ecol. Manage. Restor. 3 (2), 107-119. 
Brunckhorst, D.J., Bridgewater, P., Parker, P., 1997. The UNESCO Biosphere Reserve program comes of age: learning by doing landscape models for sustainable conservation and resource use. In: Hale, P., Lamb, D. (Eds.), Conservation Outside Reserves. University of Queensland Press, Brisbane, pp. 176-182.

Brunckhorst, D.J., Coop, P., 2001. The influence of social eco-logics in shaping novel resource governance frameworks. In: Lawrence, G., Higgins, V., Lockie, S. (Eds.), Environment, Society and Natural Resource Management: Theoretical Perspectives. Edward Elgar Academic Press, Cheltenham, UK, pp. 84-103.

Brunckhorst, D.J., Rollings, N.M., 1999. Linking ecological and social functions of landscapes: influencing resource governance. Nat. Areas J. 19 (1), 34-41.

Carpenter, S.R., Gunderson, L.H., 2001. Coping with collapse: ecological and social dynamics in ecosystem management. Bioscience 51 (6), 451-457.

Coop, P., 2003. Eco-civic landscapes: capturing civic interest in multi-scale natural resource management frameworks. PhD Thesis. University of New England, Armidale.

Cortner, H.J., Wallace, M., Burke, S., Moote, M., 1998. Institutions matter: the need to address the institutional challenges of ecosystem management. Landscape Urban Plan. 40, 159-166.

Cunningham, G.M., 1986. Total catchment management: resource management for the future. J. Soil Conserv. New South Wales 42 (1), 4-5.

Field, D.R., Voss, P.R., Kuczenski, T.K., Hammer, R.B., Radeloff, V.C., 2003. Reaffirming social landscape analysis in landscape ecology: a conceptual framework. Soc. Nat. Resour. 16 (4), 349-362.

Forman, R.T.T., 1995. Land Mosaics: The Ecology of Landscapes and Regions. Cambridge University Press, Cambridge.

Gunderson, L., Holling, C.S., Light, S. (Eds.), 1995. Barriers and Bridges to the Renewal of Ecosystems and Institutions. Columbia University Press, New York.

Holling, C.S., Meffe, M., 1996. Command and control and the pathology of natural resource management. Conserv. Biol. 10 (2), 328-337.

Johnson, K., Swanson, F., Herring, M., Greene, S., 1999. Bioregional Assessments: Science at the Crossroads of Management and Policy. Island Press, Washington, DC.

Knight, R.L., Landres, P.B. (Eds.), 1998. Stewardship Across Boundaries. Island Press, Washington, DC.

Marshall, G.R., 2001. From culture to cooperation: insights from an Australian program of collaborative environmental governance. In: Paper presented to the International Association for the Study of Common Property Inaugural Pacific Regional Meeting, Brisbane.

McKean, M., 1996. Common-property regimes as a solution to problems of scale and linkage. In: Hanna, S., Folke, C., Mäler, K.G. (Eds.), Rights to Nature: Ecological, Economic, Cultural and Political Principles of Institutions for the Environment. Island Press, Washington, DC, pp. 223-224.

Meidinger, E.E., 1997. Organizational and legal challenges for ecosystem management. In: Kohm, K.A., Franklin, J.F. (Eds.), Creating a Forestry for the 21st Century: The Science of Ecosystem Management. Island Press, Washington, DC, pp. 123145 .
Meidinger, E.E., 1998. Laws and institutions in cross-boundary stewardship. In: Knight, R.L., Landres, P.B. (Eds.), Stewardship Across Boundaries. Island Press, Washington, DC, pp. 87110.

Omernik, J.M., 1995. Ecoregions: a spatial framework for environmental management. In: Davis, W., Simon, T. (Eds.), Biological Assessment and Criteria: Tools for Water Resource Planning and Decision Making. Lewis Publishing, Florida, pp. 49-62.

Omernik, J.M., Bailey, R.G., 1997. Distinguishing between watersheds and ecoregions. J. Am. Water Resour. Assoc. 33 (5), 1-15.

Parisi, D., Taquino, M., Grice, S.M., Gill, D.A., 2004. Civic responsibility and the environment: linking local conditions to community environmental activeness. Soc. Nat. Res. 17 (2), 97-112.

Pickett, S.T.A., Cadenasso, M.L., Grove, J.M., 2004. Resilient cities: meaning, models, and metaphor for integrating the ecological socio-economic, and planning realms. Landscape Urban Plan. 69 (4), 369-384.

Power, T.M., 1996. Lost Landscapes and Failed Economies: The Search for a Value of Place. Island Press, Washington, DC.

Reeve, I.J., 1992. Sustainable agriculture: problems, prospects and policies. In: Lawrence, G., Vanclay, F., Furze, B. (Eds.), Agriculture, Environment and Society: Contemporary Issues for Australia. MacMillan, Melbourne, pp. 208-223.

Reeve, I.J., 1997. Property and participation: an institutional analysis of rural resource management and landcare in Australia. In: Lockie, S., Vanclay, F. (Eds.), Critical Landcare. Centre for Rural Social Research. Charles Sturt University, Australia, pp. 8395.

Reeve, I.J., 1998. Commons and coordination: towards a theory of resource governance. In: Epps, R. (Ed.), Sustaining Rural Systems in the Context of Global Change. Proceedings of the Conference of the Joint IGU Commission for the Sustainability of Rural Systems and the Land Use-Cover Change Study Group. University of New England, Armidale, pp. 54-65.

Reeve, I.J., Brunckhorst, D.J., Coop, P., in press. Identifying spatially bounded regions for resource governance: water catchments and 'eco-civic' regions. Soc. Nat. Res., 18.

Rollings, N.M., Brunckhorst, D.J., 1999. Linking ecological and social functions of landscapes. II. Scale and modelling of spatial influence. Nat. Areas J. 19 (1), 42-50.

Saunders, D.A., Briggs, S.V., 2002. Nature grows in straight lines-or does she? What are the consequences of the mismatch between human-imposed linear boundaries and ecosystem boundaries? An Australian example. Landscape Urban Plan. 61, 71-82.

Shannon, M.A., 1992. Community governance: an enduring institution of democracy. In: Congressional Research Service Senate Report, Symposium on Multiple Use and Sustained Yield: Changing Philosophies for Federal Land Management. Library of Congress, Washington, DC.

Shannon, M.A., 1998. Understanding Social organizations and Institutions. In: Naiman, R.J., Bilby, R.E. (Eds.), River Ecology and Management: Lessons from the Pacific Coastal Ecoregion. Springer Verlag, New York, pp. 529-551.

Shannon, M.A., 2000. Engaging rural people and catchment communities: weaving together the local and global to make our actions count. In: Brunckhorst, D.J., Mouat, D. (Eds.), Proceedings of 
the International Symposium on Landscape Futures. UNESCO Institute for Bioregional Resource Management and University of New England, Armidale.

Slocombe, D.S., 1983. Implementing ecosystem-based management: development of theory, practice and research for planning and managing a region. BioScience 43 (9), 612-622.

Stewart, W.P., Liebert, D., Larkin, K.W., 2004. Community identities as visions for landscape change. Landscape Urban Plan. 69 (2/3), $315-334$.

Terkenli, T.S., 2005. New landscape spatialities: the changing scales of function and symbolism. Landscape Urban Plan. 70 (1-2), 165-176.

Thackway, R., Cresswell, I. (Eds.), 1995. An Interim Biogeographic Regionalisation for Australia: A Framework for Establishing the National System of Reserves, Version 4.0. Australian Nature Conservation Agency, Environment Australia, Canberra.

Turner, M.B., O’Neill, R.V., Gardner, R.H., 2001. Landscape Ecology in Theory and Practice: Pattern and Process. Springer Verlag, New York.

Woodward, C., 2000. Oceans End: Travels through Endangered Seas. Basic Books, Perseus, New York.

David Brunckhorst (BSc, PhD, Dipl. Comp, Dipl. Mngmt.) was appointed to the Chair in Rural Futures at the University of New England in 2000. David has worked as a marine scientist, director of land and sea conservation programs with the former Australian Nature Conservation Agency where he established the National Reserve System Program and, principal advisor to the Federal Parliamentary Standing Committee on the Environment. He is author of more than 100 refereed papers and 5 books, and editor or co-editor of several volumes. He was awarded a UNESCO medal in July 2000 for his work on bioregional planning for integrating management issues across conservation and production landscapes.

Phil Coop (BFin.Admin, DipAgEc, MnatRes, PhD) had over 15 years experience in private sector management and finance, before undertaking his $\mathrm{PhD}$ on the social and ecological functions of landscapes. His interests now include natural resources management, landscape ecology, and spatial informatics-remote sensing and GIS analyses of social and natural resources components of landscapes.

Ian Reeve (BSc, DipNatRes, GradDipStats, MnatRes, $\mathrm{PhD}$ ) is a natural resource scientist with a $\mathrm{PhD}$ in environmental sociology. His wide range of research skills include social survey design, measurement, data collection, statistical analysis and program evaluation in both the social and natural sciences. Ian has extensive experience with the implementation of surveys in rural areas, including large scale national surveys of farmer attitudes to environmental issues in 1991 and 2000. He has also published widely on resource governance issues and resource policy history. 